\title{
En busca del lector implícito en tres versiones del relato de la niña obediente
}

\section{Ana Sofía Ramírez Heatley}

\section{Tres versiones de una niña obediente}

Encontrar versiones distintas de un mismo relato es un hallazgo frecuente en el ámbito de la literatura infantil y juvenil contemporánea. Ello se debe a una de las tendencias en la escritura de textos infantiles y juveniles que se construyen a partir de recuperaciones, reformulaciones o adaptaciones de textos previos pertenecientes al folklore o de obras clásicas que trascienden muchas veces como resultado de ese proceso de metamorfosis que las mantiene vigentes.

El estudio y comparación de las distintas versiones de un mismo relato pueden realizarse mediante enfoques muy diversos. La revisión de las diferentes reformulaciones arroja claves sobre el contexto en que se insertan las obras, los valores morales predominantes, las variaciones ideológicas y las transformaciones del concepto de infancia. Es posible estudiar aspectos semejantes en cada una de las versiones que previamente a su fijación escrita se transmitieron en forma oral.

Además, debemos considerar que cada versión de un relato es el resultado de un conjunto de decisiones más o menos conscientes que el autor toma respecto de la historia que le sirve como referencia. La fábula - argumento, mythos o estructuración de los hechos, según la define Aristóteles - es uno de los principales elementos sujeto a variaciones. Por mucho que intente apegarse a la versión previa u original, cada reformulación constituye, primero, una selección de los hechos que serán representados y, segundo, una elección de la forma o modo de representación.

Uno de los aspectos relacionados con la elección del modo como se representan los

hechos en las versiones de un mismo relato está determinado por la figura del lector implícito. Este concepto personifica el rol que desempeña el lector en un texto específico; se concibe como un conjunto de elementos que forman parte de la estructura textual en los que el lector y sus funciones son preconcebidos. El análisis comparativo de tres versiones 
sobre el motivo de la niña obediente permitirá evidenciar la relación del lector implícito en el proceso de reformulación de un texto ya conocido. Tres obras que tienen como protagonista a esta niña extremadamente disciplinada son "El cuentista" de Hector Hugh Munro, alias Saki, el "Cuento de la niña condecorada" de Jorge Ibargüengoitia e Hipersúper Jezabel de Tony Ross.

La figura del lector implícito constituye el foco de las relaciones que se establecen al colocar estos tres textos bajo un esquema de análisis comparativo. ¿Qué elementos en la estructura de estas obras buscan provocar un efecto determinado que permita afirmar la existencia de un lector implícito distinto en cada una de las versiones? Para responder esta pregunta es necesario partir de otro interrogante: ¿qué relevancia puede tener la figura del lector implícito en el estudio de las múltiples reformulaciones de una historia en común? En primer lugar, en una lectura comparativa destaca la estructuración particular de los hechos en cada una de las obras. Aunque las tres resultan muy semejantes y pueden reconocerse como versiones o reformulaciones de un texto previo común, presentan diferencias estructurales considerables. Un ejemplo de ello se evidencia en el hecho de que Saki inserta el cuento de la niña obediente dentro de un relato más amplio, lo que se muestra como un primer indicio de las decisiones tomadas en relación con la configuración de un texto y que necesariamente repercuten en las significaciones y efectos producidos. En segundo lugar, la figura de la niña obediente, presente en los tres textos, no es exactamente la misma en cada uno de ellos: se trata de una niña "horriblemente buena" en el texto de Saki, de una niña "que era gente grande" en el cuento de Ibargüengoitia y de una niña "superperfecta" en el libro-álbum de Tony Ross. La figura evoluciona de manera distinta en cada uno de los relatos y, aunque se trata de una niña obediente, el acento está puesto en diversas particularidades del personaje de acuerdo con cada una de las variaciones o reformulaciones.

En tercer lugar, la obra de Tony Ross se diferencia de las otras versiones por la siguiente característica: es un libro en el que las ilustraciones poseen un papel fundamental, interactúan con el texto y agregan significaciones a la historia.

Estos aspectos repercuten en el efecto provocado, lo que nos remite nuevamente a la figura del lector implícito. Asimismo podemos entender estas tres versiones como tres lecturas o interpretaciones de un mismo motivo que destacan, puntualizan, omiten, tergiversan, 
invierten, reformulan un mismo texto previo. De esta forma, al entender las versiones como lecturas o interpretaciones, volvemos nuevamente al campo de la estética de la recepción.

\section{El lector en el texto}

Para comprender más a fondo la figura del lector implícito resulta pertinente precisar este concepto. Para Jauss e Iser, los teóricos que desarrollaron las bases de la estética de la recepción, la manera como se lee un texto se encuentra íntimamente relacionada con la forma misma del texto (Pozuelo 1989). Por lo tanto, es necesario considerar la forma o estructura de las tres versiones que nos ocupan para poder desentrañar el rol del lector implícito.

La recepción es definida como un fenómeno interior a la textualidad, ya que el lector es quien completa la estructura esquemática de la obra literaria. Para Ingarden, los objetos representados en la obra literaria exhiben lugares o puntos de indeterminación que son completados por el lector (Pozuelo 1989).

Existen diferentes conceptos de lector para la crítica literaria. El lector ideal, uno de los más difundidos, señala las dificultades existentes en la comunicación, ya que "un lector ideal debería poseer el mismo código del autor" (Iser 1987: 57). Este tipo de lector es definitivamente una ficción, puesto que lo puede todo.

El lector implícito, como el ideal, es un constructo, aunque con un aspecto esencial que lo relaciona con la estructura del texto. De acuerdo con Iser, el lector implícito "encarna la totalidad de la preorientación que un texto de ficción ofrece a sus posibles lectores” (1987: 64). ¿Qué significa esto? Un texto ofrece determinados elementos y características que serán reconstruidos o actualizados cuando éste se ponga en contacto con su receptor. Estos elementos y características textuales pensados de antemano, planeados para que el receptor empírico pueda construir el sentido del texto, constituyen la figura del lector implícito.

Ésta es precisamente la figura que destaca en el estudio comparativo de las tres versiones del mito de la niña obediente. ¿Qué elementos en estos tres textos permiten subrayar una tendencia o preorientación hacia posibles receptores con características distintas? 
Más aún, el lector implícito, como parte de la estructura del texto, anticipa o hace evidentes los posibles efectos que provocará el texto. Hay elementos en las tres versiones del cuento de la niña obediente que buscan, por ejemplo, provocar la risa, desconcertar o romper con las expectativas del lector.

Además, el lector implícito establece una perspectiva para el lector, quien se sitúa precisamente en el lugar o el punto de mira que el texto propone. La presentación del texto, su estructura, está provista de perspectivas: el punto de vista del autor, el narrador, cada uno de los personajes y la acción junto con la ficción del lector (Iser 1987). Estas perspectivas son parte fundamental de la orientación del texto y determinan el punto de vista en que se sitúa el lector al interactuar con él; es decir, la perspectiva o el rol del lector se encuentra preestablecido en la forma de presentación del texto. El rol del lector se encuentra cifrado en todos y cada uno de estos elementos, lo que determina la importancia de la figura del lector implícito, quien conjuga las perspectivas.

Otro aspecto previamente esbozado que es necesario considerar al hablar del lector implícito se refiere a los intersticios o espacios en blanco que forman parte de la naturaleza del texto literario. Lo no dicho - según Eco 1999- o los espacios de indeterminación según Ingarden 1998 - son ausencias en el texto que predeterminan la presencia de un lector capaz de rellenar "huecos" e interpretar. Por lo tanto, las omisiones constituyen otro elemento fundamental al preguntarnos por la figura del lector implícito en las tres versiones que nos ocupan.

En síntesis, en este análisis comparativo de los textos de Saki, Ibargüengoitia y Ross, se analizarán los posibles efectos de los textos, las perspectivas que se conjugan, los elementos esenciales de la estructuración de los hechos que representan un punto de vista determinado, las presencias o elementos que rompen con las expectativas del lector y las ausencias o puntos de indeterminación dispuestos para que el destinatario intervenga.

\section{Una niña horriblemente buena}

En "El cuentista" de Hector Hugh Munro, ${ }^{1}$ mejor conocido por su seudónimo Saki, tres niños pequeños viajan en tren junto con su tía. Un solterón (the bachelor) tiene la "suerte" de compartir el vagón con tan inquieta comitiva y observa desde cerca las torpes estrategias de la implacable mujer para mantener a sus sobrinos en calma. Los pequeños hacen muchas 
preguntas que la tía no sabe cómo responder: “¿Por qué se llevan a los borregos de ese prado?" pregunta Cyril. ${ }^{2}$ Consciente de que los borregos son probablemente conducidos al matadero, la tía ofrece respuestas "protectoras", que intentan ocultar la crudeza de ciertos aspectos de la vida y que, además, no satisfacen a los niños. Como último recurso, la tía sugiere que escuchen un cuento; así, relata la historia de una niña buena que es salvada de ser embestida por un toro, precisamente por su bondad y buen comportamiento. Los niños no parecen entusiasmarse con la historia y pronto vuelven a reanudar las actividades que hacen patente su aburrimiento.

El solterón, que hasta el momento había sido únicamente observador, critica la labor de la tía como cuentacuentos. Ella reacciona sugiriendo que cuente él mismo una historia a sus sobrinos. En ese momento deja de ser observador para convertirse en cuentista, abriendo una puerta hacia un mundo irreverente al que los niños no habían sido nunca convocados.

El cuentista toma como punto de partida la historia de la tía, por lo que teje un relato donde Bertha, la protagonista, es una niña tan obediente que es condecorada con tres medallas: las de obediencia, puntualidad y buen comportamiento. Al principio todo parece indicar que la historia del solterón seguirá un rumbo previsible de acuerdo con lo políticamente correcto, pero el relato toma un giro imprevisto y es aderezado con una dosis de vitalidad y autenticidad que rompe con las expectativas de los pequeños y despierta su interés.

Bertha no sólo es buena, sino que es descrita como una niña "horriblemente buena". Ambas palabras en conjunción constituyen una novedad para los niños, como indica el narrador: "La palabra horrible en unión con la bondad era una novedad [...]. Parecía introducir un halo de verdad que estaba ausente en los cuentos de la tía sobre la infancia” (1978: 236).

La bondad de Bertha llega a los oídos del príncipe, quien le permite la entrada a sus jardines. En una ocasión, mientras Bertha visita esos jardines, un lobo hambriento se acerca, atraído por la presencia de los cerdos que vivían ahí. Bertha se oculta rápidamente entre los arbustos para proteger su vida. El lobo seguramente no la habría descubierto si el susto no la hubiera hecho temblar, provocando el choque y tintineo de las medallas. El animal, nada tonto "se abalanzó a los arbustos, sus ojos gris pálido brillaban con ferocidad 
y triunfo, y arrastró a Bertha hacia fuera y la devoró hasta el último trozo. Todo lo que quedó de ella fueron sus zapatos, jirones de ropa y las tres medallas de bondad" (1978: 238).

La perspectiva del lector está orientada por el narrador, quien cuenta la historia mostrando los hechos desde su propio punto de vista. Así, el narrador omnisciente en "El cuentista" cumple un papel fundamental, puesto que establece un punto de vista determinado desde el cual el lector deberá leer el relato. El narrador ordena el mundo de ficción, establece una jerarquía de valores, determina el rol y el punto de vista del lector, aspectos que constituyen una parte esencial de la figura del lector implícito en este relato.

Los tres pequeños personajes se fascinan con la historia: "Comenzó mal, dijo la más pequeña de las niñas pequeñas, pero tuvo un final hermoso" (1978: 238). En cambio, la tía comenta indignada: “ $¡$ Una historia sumamente inapropiada para los niños! Ha socavado el efecto de años de cuidadosa enseñanza" (1978: 239).

El lector implícito se sitúa en la confluencia de perspectivas que generan los personajes y el narrador de este relato. No obstante, su propia perspectiva y el rol del lector se encuentran encauzados por el narrador, quien mira con recelo la actitud de una mujer adulta que tergiversa el mundo mediante un relato con tal de construir una torpe enseñanza: los niños que tienen un buen comportamiento son absueltos sin importar el peligro al que sean sometidos.

Es probable que algunos lectores consideren el relato del cuentista inapropiado para los niños; otros, igual que el narrador, verán en él una dosis de frescura y subversión que le otorga cierta audacia. Sin embargo, el punto de vista del lector implícito subyace en el texto mismo. No es equiparable al de ninguno de los personajes, puesto que cada uno de ellos (la tía, el cuentista y los tres pequeños) mantienen una postura distinta frente a los hechos; así el lector implícito se sitúa en el lugar donde convergen todas y cada una de las perspectivas, incluida la del narrador. La tía tiene una manera distinta u opuesta a la del cuentista de concebir el mundo y la manera como éste debe de ser representado en las historias destinadas a los niños. La dimensión moral es el aspecto central dentro del relato que la tía cuenta a sus sobrinos. Por lo tanto, la protagonista del cuento de la tía es una niña buena, a secas, y la bondad en toda su abstracción es la clave para que la niña tenga muchos amigos y finalmente sea rescatada. 
En cambio, para el cuentista es más importante que un relato sea auténtico, verosímil, congruente y cercano a las circunstancias y aspectos esenciales de la vida; por consiguiente, el cuentista coloca la "verdad" de la ficción por encima de la intención moralizante. Sólo cuando un relato se muestra fiel a sí mismo y se vincula íntimamente con la vida - aunque aparezcan elementos poco comunes como jardines llenos de cerdos - se abre la posibilidad de la comunicación, por lo que los niños escuchan atentamente la historia del cuentista.

Para Graciela Montes las características de uno de sus relatos favoritos de la infancia son la audacia en el imaginario —en la construcción del mundo de fícción-, la rebeldía y la justicia (1999). Estas tres características están presentes en el relato del cuentista, que resulta inesperado y asombroso para los niños. La rebeldía se hace patente desde el momento en que el cuentista parodia el relato de la tía, invirtiendo el esquema al presentar a la protagonista como una niña "horriblemente buena". El desenlace hace justicia al relato, pues retoma las tres medallas y, congruente con el contexto en el que se encuentra la protagonista, hace de ellas un estorbo, un elemento trágico, más que un medio de salvación. Sencillamente una niña "horriblemente buena" no puede tener un buen fin; su comportamiento es exagerado, no se apega a la naturaleza humana. Además, aunque el desenlace pueda ser considerado cruel, inapropiado, políticamente incorrecto $o$ desconcertante, es verosímil y congruente con cada elemento del relato.

Por lo tanto, el lector implícito hace patente el efecto de "El cuentista" en su totalidad. Al formar parte de la estructura del texto, posee una perspectiva global en la que se involucran los desconciertos de la tía, la admiración genuina de los tres pequeños, la actitud crítica e intuitiva del cuentista, quien comprende las necesidades del relato de ficción, así como la visión del narrador que favorece al cuentista y desaprueba el fallido intento de la tía. Orientado por el narrador - figura tras la cual se oculta el autor del relato-, el lector implícito es encauzado a comprender la situación de forma análoga a la que se manifiesta en frases como: "Ella [la tía] comenzó una vacilante y deplorable historia de poco interés sobre una niña pequeña" (1978: 235). Los calificativos que el narrador emplea en esta frase manifiestan explícitamente la visión de un autor que se disuelve u oculta tras esta figura. Así, la orientación del lector implícito en "El cuentista" está 
determinada por la perspectiva predominante en el relato: colocar las leyes de la ficción y la naturaleza por encima de la intención moralizante.

\section{Una niña que era gente grande}

Jorge Ibargüengoitia ${ }^{3}$ retoma el motivo de la niña obediente en el "Cuento de la niña condecorada". Mandolina, la protagonista, es una niña que actúa como un adulto. Más aún, adopta la postura represora y coercitiva de algunos mayores, señalando a los pequeños que cometen algún estropicio o simplemente a quienes se comportan como niños.

En la escuela siempre actúa de manera semejante a la maestra, ya que lleva un registro de los retardos, asistencias, puntos buenos y malos de los demás niños. Evidentemente una niña con ese comportamiento no goza de la simpatía de sus compañeros, así que responde ante las agresiones $\longrightarrow$ lo que ella considera como tales - registrando notas malas para quienes la molestan y consolándose con una buena dosis de puntos buenos.

Al igual que la Bertha de Saki, Mandolina obtiene algunas medallas al finalizar el año: "La medalla de Aplicación, la de Puntualidad, la de Comportamiento, la de Aritmética, la de Español y la de Ciencias Naturales" (1989: 108). No obstante, en el relato de Ibargüengoitia se emplea el recurso de exageración: Mandolina recibe tres medallas más que Bertha. Además, las medallas de Bertha y Mandolina representan la importancia que tienen determinados aspectos de acuerdo con la ideología y la concepción educativa de la época. El relato de Ibargüengoitia, escrito en pleno siglo XX, destaca la importancia del currículo escolar; así, una niña no podría ser tan "buena" si no obtuviera exitosas notas en las distintas disciplinas académicas que se imparten en la escuela.

El elemento de ruptura con el ambiente escolar y "ordinario" aparece cuando la protagonista se introduce en el bosque, espacio tradicionalmente extraño y peligroso que contrasta con la seguridad y calidez del hogar (o la escuela). Mandolina no cree las historias que cuenta la gente acerca de las amenazas del bosque. Niega la existencia de los lobos, porque según ella son personajes de ficción: "Sólo aparecen en los cuentos para niños, como el de Caperucita Roja, por ejemplo" (1989: 107). Esta afirmación coloca a la protagonista nuevamente dentro del mundo de los adultos, quienes presumen de tener sentido común. Por lo tanto, el pensamiento de esta niña se aproxima más al de un adulto que al de cualquier otro niño, generalmente plagado de imaginación y elementos mágicos. 
Así, esta incredulidad de la protagonista, contrariamente a lo que el lector pudiera pensar al comienzo de la historia, se convierte en el error trágico de Mandolina.

Tras haber obtenido las seis medallas, la pequeña cruza el bosque y despierta al lobo con un metálico tilín, tilín. El lobo, que estaba en ayunas, camina hacia el lugar de donde provenía el sonido. Mandolina se esconde detrás de un árbol, pero el miedo hace sonar las medallas.

Sin embargo, el lobo de este cuento no parece ser muy perspicaz y pasa de largo sin descubrir el escondite de Mandolina, quien del susto se volvió simpática, acota el narrador. Esta última frase, con la que cierra el cuento, apela al lector quien deberá realizar la misma asociación que hizo la protagonista: la aparición del lobo no es gratuita en el relato y se debe principalmente a su comportamiento, condecorado por muchos, repudiado por otros. Esta niña se apega a los hechos comprobables o evidencias del mundo, por lo que hace caso omiso a las "habladurías" de las personas. Paradójicamente, su actitud, lejos de ser sinónimo de madurez y sentido común, representa una especie de ceguera o visión limitada: así como no puede detectar los peligros del bosque, tampoco es capaz de hacer un análisis de conciencia, sino hasta el encuentro con el lobo que le permite recapacitar y volverse agradable.

El lector implícito en este relato activa el funcionamiento de la ironía y la sátira. La historia perdería todo su sentido si el lector llegara a situarse en la perspectiva de un adulto como la tía del cuento de Saki o las mamás que utilizaban a Mandolina como ejemplo para sus hijos. Por ello, el juego está precisamente en contrastar el comportamiento de Mandolina, alabado por los adultos del cuento, con el comportamiento que caracteriza a la infancia.

Ibargüengoitia sitúa la voz y perspectiva del adulto en las mamás y la maestra que quieren que los demás niños sean como Mandolina. Asimismo, hace de la protagonista una niña odiosa ante los ojos de los demás pequeños por actuar como un adulto. De esta forma, el lector implícito ocupa el lugar que el texto vuelve factible para él, de manera que permita el funcionamiento de la ironía: una niña condecorada, bien portada y con sentido común es digna de recibir un castigo, primera consideración irónica. El segundo elemento irónico dentro del desenlace es que el lobo-verdugo resulta tontísimo y no logra comérsela. 
En síntesis, la perspectiva del lector implícito en el "Cuento de la niña condecorada" hace posible el absurdo e hipérbole en la actitud de la protagonista. Por este motivo, Mandolina adquiere en el texto un carácter distinto al de los héroes en los relatos, a pesar de poseer tantas "cualidades". Sin embargo, el lector configurado en esta obra también participa de la visión del adulto; de alguna manera, reconoce el punto de vista de esas figuras que condecoran a la protagonista. Así, la exageración o hipérbole que predomina en el comportamiento de Mandolina se convierte, al mismo tiempo, en una sátira dirigida a los adultos que desean que los pequeños se comporten como mayores. El humor y el desenlace donde la protagonista se salva y recapacita "suavizan" o vuelven digerible la crítica subyacente en el texto.

En el relato de Saki, por el contrario, la crítica explícita a la visión moralizante de la tía se refuerza con las acotaciones del narrador, las reacciones de los niños y los reproches del cuentista. En cambio, en el cuento de Ibargüengoitia se utiliza el humor y la ironía, por lo que el lector resulta fundamental en la construcción del sentido. El papel del lector implícito se destaca en los momentos humorísticos del texto, justo cuando predominan la exageración y el absurdo, ya que su presencia hace posible el efecto. La ironía que detenta el carácter de la protagonista — una niña condecorada que no es simpática y se comporta como adulto - es otra de las características del texto que refuerza la presencia de un lector implícito. Por consiguiente, mientras que la crítica en la historia de Saki es explícita en los diálogos de los personajes y en la voz del narrador, en el "Cuento de la niña condecorada" la crítica se manifiesta como un juego de humor e ironía que debe ser desentrañado por el lector.

\section{Una niña superperfecta}

Hipersúper Jezabel de Tony Ross, ${ }^{4}$ a diferencia de "El cuentista" y el "Cuento de la niña condecorada", se encuentra abiertamente dirigido a un público infantil: las ilustraciones y el formato son muestra de ello. Como muchos otros libros del autor, éste retoma un argumento clásico de la tradición infantil y lo actualiza mediante aportaciones del texto y las imágenes. Así, en este libro-álbum el arquetipo de la niña obediente obtiene una nueva fisonomía o, mejor aún, se le otorga por primera vez un rostro, ya que Ross ilustra la historia. 


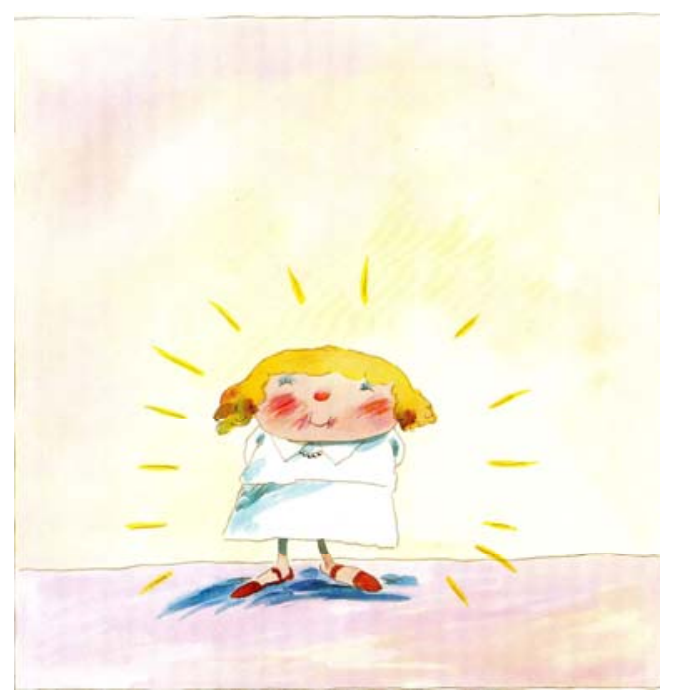

(C) Tony Ross, 1988. Super Dooper Jezebel, Andersen Press, Ltd, Londres.

Jezabel, como dictan las ilustraciones y reitera el texto, es una niña impecable, extraordinaria, superperfecta. Un ejercicio interesante para consolidar esta apreciación consiste en observar las ilustraciones sin reparar en el texto: ellas destacan claramente cuán perfecta es la protagonista y lo hacen por oposición a las actitudes de otros personajes de su edad. La estrategia de oponer el caos y el orden hiperbólico -el comportamiento desordenado de los niños versus la perfección y pulcritud de Jezabel- se emplea en distintas escenas: cuando se sienta a la mesa, Jezabel deja el plato limpio y los cubiertos perfectamente acomodados; en cambio, su compañera de mesa deja el lugar hecho un desastre.

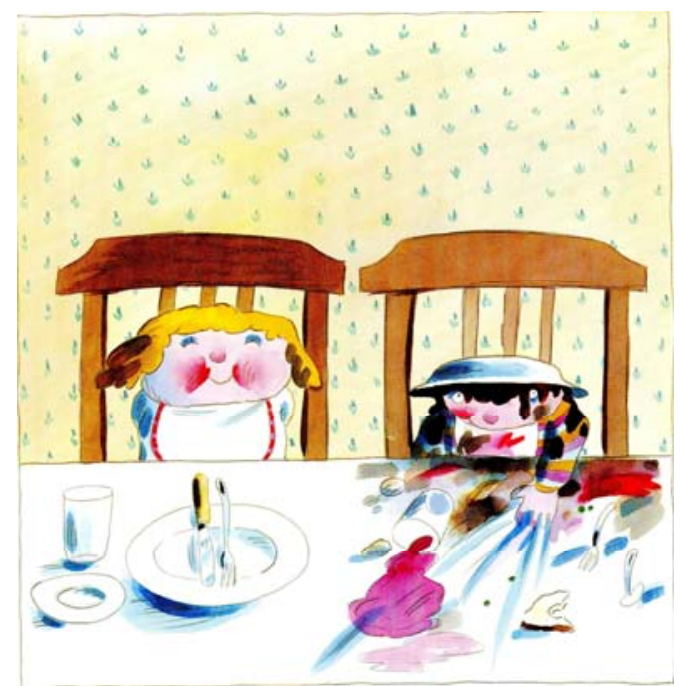

(C) Tony Ross, 1988. Super Dooper Jezebel, Andersen Press, Ltd, Londres. 
Otras ilustraciones destacan las particularidades de la protagonista al mostrarla realizando actividades que la mayoría de los niños, e incluso de los adultos, no realizarían con tal diligencia. Ordena su habitación, limpia los excrementos del gato, escribe cartas de agradecimiento, resuelve operaciones complicadas de matemáticas, se toma la medicina. Todas estas actitudes hacen de Jezabel una niña particular, distinta..., sencillamente superperfecta. Sin embargo, el lector comienza a sentir cierta aversión hacia el personaje al descubrir que, además de ser perfecta, Jezabel corrige y reprende a los demás pequeños que no se comportan como ella.

De manera gradual, una transformación se opera en la protagonista. Este cambio es patente en las ilustraciones, aun cuando el texto continúa narrando y describiendo con cierta neutralidad los hechos. La niña súper perfecta y orgullosa de sí misma recibe una medalla del primer ministro. Más aún, se construye un monumento en su honor en el parque "para que a todo el mundo le entraran también ganas de ser perfecto" (1990: 21). Tras pasar esta página, el lector se encuentra con una Jezabel de gesto transformado: petulante, orgullosa por aparecer en televisión. Así, la niña superperfecta muestra una actitud hostil que, aunada a otras manifestaciones de su comportamiento, la alejan de cualquier rasgo de simpatía que aún pudiera tener. La escena se tiñe de colores oscuros cuando la protagonista muestra: "Las supercopas que había ganado por ser tan superlimpia, tan superpulcra, tan superamable y por ser, con mucho, la mejor en matemáticas, lectura y caligrafía" (1990: 23).

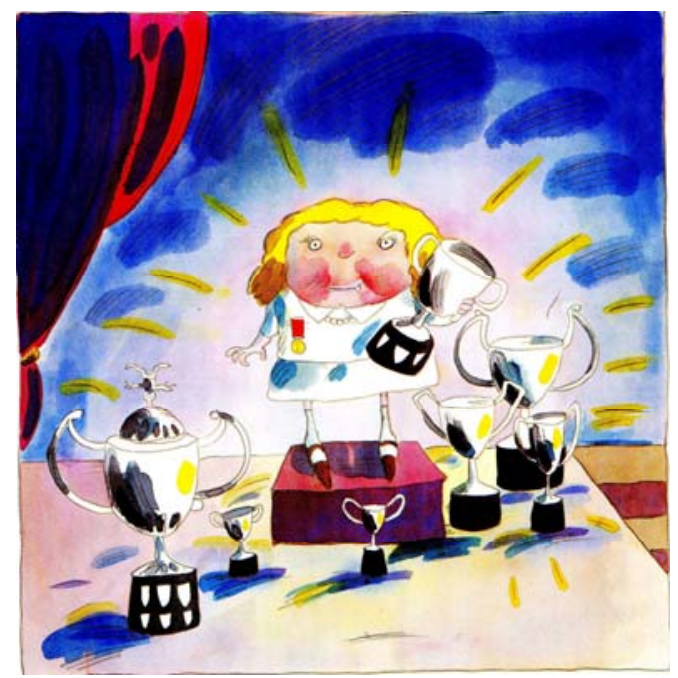

(C) Tony Ross, 1988. Super Dooper Jezebel, Andersen Press, Ltd, Londres. 
Estos colores otorgan cierto dramatismo al personaje, cuya vanidad parece acrecentarse a medida que recibe las sucesivas distinciones. Dos pequeños colmillos asoman por las comisuras de sus labios cuando se encuentra rodeada por las preseas. Literalmente Jezabel, quien ahora encarna la perfección, comienza a teñirse de tonalidades oscuras, que destacan su egocentrismo y altivez.

La transformación del personaje da rienda suelta al carácter perverso de la niña. Más que por causar un daño intencionadamente, la protagonista resulta perversa en la medida en que corrompe el orden o se distancia del comportamiento habitual de una niña de su edad. Las ilustraciones de estas escenas agregan intensidad de color y rasgos angulosos al rostro de Jezabel; en el texto hay una profusión de adjetivos que destacan la excelencia hiperbólica del comportamiento: superperfecta, superlimpia, superpulcra, superamable.

Estos elementos, presentes tanto en el texto como en las ilustraciones, producen un determinado efecto y dirigen el rol y las reacciones del lector. El texto comunica que Jezabel es superperfecta, pero las ilustraciones expresan lo contrario: que esta niña también es supervanidosa, superorgullosa, superinsoportable. En el desenlace, el texto reitera que “Hipersúper Jezabel nunca hacía nada mal... como los otros niños” (1990: 24-25). Los niños gritan: “¡Corre, Jezabel!”, y ella responde: “No. Correr es de mala educación. Hay que caminar siempre despacito. Si corres, se te caen los calcetines" (1990: 25).

En este momento el lector se encuentra expectante. El acto de pasar la página produce el acontecimiento del desenlace: Jezabel es devorada por un cocodrilo. “¡Clump!”, apunta el texto, sin nada más que decir. La ilustración resulta suficientemente explícita y no hay lugar para las palabras. En un globo de texto que parece provenir de la doble página anterior, aún se escuchan los gritos de los niños quienes comentan, demasiado tarde, que un cocodrilo se escapó del zoológico. Las últimas dos páginas son una especie de epílogo humorístico que disminuye la tensión del final.

En Hipersúper Jezabel, el lector implícito, además de estar presente en el texto, se encuentra configurado en las imágenes y en cada uno de sus detalles para elaborar en forma más compleja el carácter y la naturaleza de la protagonista. Todos los elementos se conjugan para orientar la perspectiva del lector y hacer del desenlace un hecho catártico más que terrorífico. 
La crítica acerca del comportamiento de Jezabel está presente en las ilustraciones, mientras que en el texto el narrador sólo se encarga de subrayar la supuesta perfección de la protagonista. Tanta excelencia se vuelve insoportable para el lector, lo que hace de Jezabel una niña perversa y hostil, más que un personaje a quien deba rendírsele admiración o respeto. Los relatos de Saki e Ibargüengoitia no cuentan con el recurso de la ilustración, por lo que cualquier comentario adverso respecto de la protagonista se encuentra presente en el texto, se hace explícito en la medida en que lo expresa el lenguaje, aunque para ello se utilicen recursos como la ironía o el humor negro. En cambio, la obra de Tony Ross otorga funciones distintas al texto y a las ilustraciones; el papel del lector es orientado por ambos, aun cuando el texto afirme maravillas de Jezabel y las ilustraciones lo contradigan.

\section{Del lector implícito al goce del lector}

En estas tres versiones del tema de la niña obediente hemos seguido de cerca el papel que cumple el lector al ser orientado por los diferentes elementos y recursos presentes en las obras. A manera de conclusión, es posible afirmar que estos tres textos, a pesar de retomar un mismo argumento/motivo, poseen diferentes "fuerzas internas" que dirigen y predeterminan el papel que jugará el lector al ponerse en contacto con el texto y generar esa mágica alianza que insufla vida a la obra.

El lector implícito es un elemento de la configuración artística que predetermina las reacciones y expectativas del lector. Este elemento permite que la obra adquiera sentido, que los juegos irónicos y humorísticos cumplan su función, que el carácter de la protagonista sea comprendido tal como conviene a los fines del relato. Bertha, Mandolina y Jezabel son protagonistas distintas en la medida en que los relatos destacan unas $\mathrm{u}$ otras características; las tres encuentran diferentes finales: dos son devoradas y una cambia de actitud. Las obras que ellas protagonizan cumplen con la función de exagerar su bondad y obediencia, por lo que el lector las percibe ajenas y distantes. El lector implícito encauza las reacciones de los posibles lectores y, al mismo tiempo, establece sus funciones. Así, en el momento en que estos relatos llegan a las manos de los niños, jóvenes o adultos, los textos tienen preparadas determinadas tareas para ellos que implican desentrañar distintas cuestiones, imaginar o anticiparse a los hechos, interpretar y, sobre todo, estar atentos a los efectos y retos que plantean estas tres versiones del cuento de la niña obediente. 
El lector implícito carece de una edad precisa, sin importar que la obra presuponga un destinatario. En todo caso, el lector se sitúa en la confluencia de perspectivas que plantean el narrador, los personajes, las ilustraciones, y obtiene sus propias conclusiones. La lectura es un proceso complejo mediante el cual el texto y cada uno de sus elementos actúan de manera sinérgica. Estas tres obras ponen en marcha distintas estrategias y plantean lectores implícitos dispuestos a discernir entre la bondad y perfección o la extrema bondad y extrema perfección, sin importar su edad. Por lo tanto, la variedad de recursos, perspectivas, discursos y las intrincadas relaciones que se establecen entre estos elementos no son necesariamente proporcionales a la edad del lector a quien se orienta la obra. El desafío de la lectura está presente en cada una de estas tres versiones y nuestro principal papel como lectores, tal como lo establece el lector implícito, consiste en lograr que los elementos de la obra confluyan, se integren de manera congruente para conseguir la merecida satisfacción y el goce de haber participado en la construcción de mundos y personajes de ficción en los que es posible reconocernos.

\section{Referencias Bibliográficas}

Aristóteles (1974) Poética de Aristóteles. Madrid: Gredos.

Colomer, T. (1999) La reformulación del cuento popular en la literatura infantil moderna. En Introducción a la literatura infantil y juvenil, pp. 75-80. Madrid: Síntesis.

Eco, U. (1999) Lector in fabula. La cooperación interpretativa en el texto narrativo. $4^{a}$ ed. Barcelona: Lumen.

Flor, J. y J. G. Sobrino (1992) Entrevistamos a Tony Ross. Peonza. Boletín Trimestral de Literatura Infantil. Santander: Asociación Cultural Peonza: 21-29.

Ibargüengoitia, J. (1989) Cuento de la niña condecorada. En Piezas y cuentos para niños, pp. 107-109. México: Joaquín Mortiz.

Ingarden, R. (1998) La obra de arte literaria. México: Taurus, Universidad Iberoamericana.

Iser, W. (1987) El acto de leer: Teoría del efecto estético. Madrid: Taurus.

Montes, G. (1999) Scherezada o la construcción de la libertad. En La frontera indómita. En torno a la construcción y defensa del espacio poético, pp.15-31. México: F.C.E.

Pozuelo Yvancos, J. M. (1989) Poética de la recepción. En Teoría del lenguaje literario. $2^{a}$ ed., pp. 105-127. Madrid: Cátedra.

Ross, T. (1990) Hipersúper Jezabel. Madrid: SM.

Saki (1978) The Storyteller. En Williams, E. (comp.) Short Stories, pp. 234-239, Londres: Dent.

Referencia de la autora:

Ana Sofía Ramírez Heatley obtuvo el título de Licenciada en Literatura Latinoamericana por la Universidad Iberoamericana (UIA) y cursó el Máster en Libros y Literatura Infantil y Juvenil 
impartido por la Universidad Autónoma de Barcelona (UAB) y el Banco del Libro de Venezuela. Fue asistente de investigación de la doctora Laura Guerrero Guadarrama en un proyecto de literatura infantil auspiciado por el Conacyt. En la UIA, ha impartido los cursos de Introducción a la Literatura, Taller de Redacción e Introducción a la Literatura Infantil y Juvenil y coordinó el diplomado de Literatura Infantil y Juvenil. Ha publicado algunos textos sobre libros para niños en revistas especializadas. Fue editora de libros infantiles y juveniles en Ediciones SM y actualmente colabora en esta misma editorial en un proyecto de redición de novelas clásicas mexicanas para jóvenes lectores.

E-mail: estrofa@hotmail.com

\footnotetext{
${ }^{1}$ Nació en Burma (hoy Myanmar) en 1870 y murió en 1916 durante la Primera Guerra Mundial. Perdió a su madre a los dos años de edad y fue criado en Inglaterra, junto con sus dos hermanos, por su abuela y dos tías estrictas. Estas figuras severas han sido representadas en "El cuentista" ("The Storyteller"), relato breve que contrasta dos puntos de vista relativos a las características de las historias destinadas a los niños.

${ }^{2}$ La traducción de este texto escrito originalmente en inglés es mía.

${ }^{3}$ Nació en 1928 en Guanajuato, México, y murió en 1983 en Madrid. Su obra, de aguda ironía y humor audaz, está dirigida principalmente a los adultos, aunque en 1989 la editorial Joaquín Mortiz reunió un conjunto de textos del autor donde predominan los niños, sus peripecias y algunos personajes de la tradición infantil. Muchos de estos cuentos son parodias de textos ya conocidos, como el "Cuento de la niña condecorada".

${ }^{4}$ Escritor e ilustrador nacido en Londres en 1938 que ha creado un discurso incisivo y perspicaz por medio de sus ilustraciones. En 1988 publicó Super Dooper Jezebel, libro que en 1990 fue traducido al español por SM España con el título de Hipersúper Jezabel.
} 